\title{
Analysis of the emotional strain influence on the indicators of the heart rhythm variability in students
}

\author{
Vera Krivobokova ${ }^{1}$, Maria Kiseleva ${ }^{1}$, Andrey Gryaznykh ${ }^{2 *}$ \\ ${ }^{1}$ Kurgan State University, 640020, Kurgan, Russia \\ ${ }^{2}$ Yugra State University, 628012, Khanty-Mansiysk, Russia
}

\begin{abstract}
To determine the features of the cardiovascular system functional state in students using some indicators of heart rate variability under emotional strain. The research involved 67 male students with an average level of daily motor activity. The age range corresponded to 18 - 23 years. All the examined in the personal history had no deviations in health status and were considered to belong to the main medical group. The tonic activity of the autonomic nervous system in the normal condition was determined using the rhythmocardiographic method on the "Varicard 2.51" hardwaresoftware complex according to the indicators of heart rate variability mathematical analysis. Cardio intervals were recorded in the normal condition and under conditions of emotional stress (the examination session was a model of stress). The analysis of heart rate variability was carried out on the basis of the statistical analysis indicators evaluation - SDNN, pNN50 and variational pulsometry - Mo, AMo, MxDMn, IN. Depending on the initial tonicity of the autonomic nervous system, all examined students were divided into groups: vagotonics, normotonics and sympathotonics. Among the determined values, the examination stress had the greatest impact on the stress index and the share of neighboring RR intervals, which differ by more than $50 \mathrm{~ms}$. If the stress index significantly increased in students with vago- and normotonia, the proportion of neighboring RR intervals, differing by more than $50 \mathrm{~ms}$, decreased in all the studied groups Taking an exam led to psycho-emotional stress of the body. It caused autonomic provision restructuring of cardiac activity due to an increase in the sympathetic effect. The results of the research may be of interest to all participants of the educational process.
\end{abstract}

\section{Introduction}

Recently, there have been a lot works by both domestic and foreign authors, paying great attention to the specifics of the regulation mechanisms and functioning of the cardiovascular system in schoolchildren and students $[1,6,8,10,11,15,16,17,19,21,22]$. To analyze the state of health, as well as the body functional reserves, the heart rate variability (HRV) method is often used. Based on the researches of recent years, it has been stated that the HRV method allows evaluating a person's vegetative status comprehensively, tonicity of central nervous and hormonal influences, as well as determining the dominant mechanisms of heart rhythm regulation. The study of heart rate variability is an important prognostic and diagnostic value for the human body state study as a whole $[2,7,18]$.

Examination stress is a fairly convenient and repeated model of emotional stress that occurs with the active participation of the autonomic nervous system. Taking into consideration that exam stress affects hundreds of thousands of students every year, the research of the occurrence of autonomic reactions under stress, as well as the analysis of typological individual shifts, is relevant as it relates to health protection issues $[3,4,5,9,12,13,14,20]$.

In this regard, the purpose of the study was to analyze the features of the cardiovascular system functional state in students, using some indicators of heart rate variability under emotional strain.

\section{Materials and Methods}

The research involved 67 male students with an average level of daily motor activity. The age range corresponded to 18 23 years. All the examined in the personal history had no deviations in health status and were considered to belong to the main medical group. All the examined gave informed written consent to physiological studies. Also, while carrying out the research, the approval of the ethics commission of the Kurgan State University, Russia for the conduct of this study was received.

A two-stage research was proposed. The initial stage was carried out in the normal condition (during the semester training), and the second in the conditions of a simulated emotional stress - an examination session.

Using the rhythmocardiographic method (PAC "Varicard 2.51"), the vegetative status of the body was recorded according to indicators of heart rate variability. Heart rate was recorded in the morning in lead II in a sitting position. The recording time was 5 minutes for 300 cycles. While assessing rhythmocardiography, the following indicators were calculated: mode (Mo, ms), characterizing the activity of the humoral regulation channel, mode amplitude (AMo,\%),

\footnotetext{
${ }^{*}$ Corresponding author: anvit-2004@ mail.ru
} 
reflecting the activity of the sympathetic part of the autonomic nervous system, standard deviation of cardio intervals (SDNN, ms), the proportion of neighboring RR-intervals differing by more than $50 \mathrm{~ms}$ (pNN50,\%) and variational range $(\mathrm{MxDMn}, \mathrm{ms})$, representing the activity of the parasympathetic department. The strain index was determined (IN = AMo $/ 2$ x Mo x MxDMn, standard units). This indicator displays the total activation of the body and the degree of the autonomic balance shift towards the dominance of the sympathetic department over the parasympathetic one $[2,15,18]$.

Statistical analysis was performed using parametric (Student's $t$-test,) and non-parametric (Mann-Whitney $U$-test, sign criterion) statistics depending on the normality of the data distribution. Differences and correlations were considered statistically significant at level $\mathrm{p}<0.05$.

\section{Results and Discussion}

In this work, the analysis of heart rate variability was carried out on the basis of the statistical analysis evaluation indicators - SDNN, pNN50 and variational pulsometry - Mo, AMo, MxDMn, IN.

Based on the normal condition data, while evaluating the vegetative status of students, the index of regulatory systems tension was focused on (IN). Based on the results of the research by Yu. V. Shcherbatykh [16], all students under research were divided into three groups: vagotonics, normotonics, and sympathotonics (Fig. 1). The first group included the examined with a stress index of not more than 30 standard units - those with a predominant tonicity of the ANS parasympathetic department, the second comprised the ones from 31 to 120 standard units - those with normotonia, and the third group was with the index from 121 to 300 standard units those with a predominant tonicity of the ANS sympathetic department.

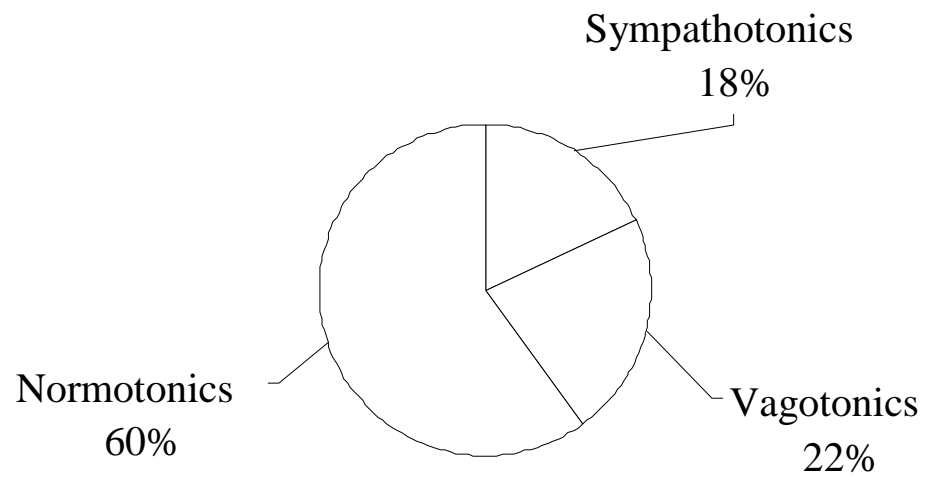

Fig. 1. Percentage distribution of young men according to their initial vegetative status

In the normal conditions, the values of standard square deviation (SDNN, ms) characterizing the effect of the parasympathetic department of the autonomic nervous system on heart activity differed between groups $(\mathrm{p}<0.05)$. This indicator increased in the series of sympathotonics $\rightarrow$ normotonics $\rightarrow$ vagotonics.

Table 1. Parameters of heart rate variability $(M \pm m)(n=67)$

\begin{tabular}{|l|l|l|l|l|}
\hline \multicolumn{2}{|l|}{ Parameter } & \multicolumn{1}{|c|}{$\begin{array}{c}\text { Vagotonics } \\
(\mathrm{n}=15)\end{array}$} & \multicolumn{1}{c|}{$\begin{array}{c}\text { Normotonics } \\
(\mathrm{n}=40)\end{array}$} & \multicolumn{1}{c|}{$\begin{array}{c}\text { Sympathotonics } \\
(\mathrm{n}=12)\end{array}$} \\
\hline \multirow{2}{*}{$\begin{array}{l}\text { SDNN, MS } \\
\text { SDNN, ms }\end{array}$} & physiological rest & $94.0 \pm 4.18$ & $54.1 \pm 1.78^{*}$ & $35.6 \pm 1.57^{* / * * *}$ \\
\cline { 2 - 5 } & emotional strain & $63.8 \pm 5.36^{* * * *}$ & $46.9 \pm 2.76^{* / * * *}$ & $36.0 \pm 4.74^{*}$ \\
\hline $\begin{array}{l}\text { Mo, Ms } \\
\text { Mo, ms }\end{array}$ & physiological rest & $917 \pm 22.57$ & $840 \pm 23.58^{* *}$ & $735 \pm 32.13^{* / * *}$ \\
\cline { 2 - 5 } & emotional strain & $764 \pm 31.18^{* * *}$ & $768 \pm 19.21^{* * *}$ & $717 \pm 22.48$ \\
\hline $\begin{array}{l}\text { AMo, \% } \\
\text { AMo, } \%\end{array}$ & physiological rest & $20.3 \pm 1.48$ & $37.6 \pm 1.18^{*}$ & $57.1 \pm 1.96^{* / * *}$ \\
\cline { 2 - 5 } & emotional strain & $36.5 \pm 3.34^{* * *}$ & $47.8 \pm 3.20^{* / * * *}$ & $59.7 \pm 7, .29^{*}$ \\
\hline $\begin{array}{l}\text { MxDMn, Mc } \\
\text { MxDMn, ms }\end{array}$ & physiological rest & $446 \pm 15.78$ & $279 \pm 8.93^{*}$ & $182 \pm 11.02^{* / * *}$ \\
\cline { 2 - 5 } & emotional strain & $317 \pm 21.37^{* * *}$ & $233 \pm 12.08^{* * * * *}$ & $170 \pm 14.62^{*}$ \\
\hline
\end{tabular}




\begin{tabular}{|c|c|c|c|c|}
\hline \multirow{2}{*}{$\begin{array}{l}\text { IN, standard } \\
\text { units. }\end{array}$} & physiological rest & $24.8 \pm 1.27$ & $84.6 \pm 4.87^{*}$ & $221 \pm 23.75^{* * *}$ \\
\hline & emotional strain & $80.5 \pm 14.32^{* * *}$ & $161 \pm 21,30^{* / * * * *}$ & $237 \pm 55.87^{*}$ \\
\hline \multirow{2}{*}{$\begin{array}{l}\text { pNN50, \% } \\
\text { pNN50, \% }\end{array}$} & physiological rest & $47.0 \pm 3.77$ & $24.9 \pm 2.62^{*}$ & $4.5 \pm 0.98^{* * * *}$ \\
\hline & emotional strain & $22.4 \pm 4.88^{* * *}$ & $11.6 \pm 2.31^{* * *}$ & $1.8 \pm 0.42^{* / * * / * * *}$ \\
\hline
\end{tabular}

Similar changes were observed in terms of the variational range (MxDMn, ms), the share of close RR-intervals, differing by more than $50 \mathrm{~ms}$ (pNN50,\%), as well as SDNN. They characterize the influence of the vagotonus. And in mode parameters (Mo, ms) they characterize the activation level of the humoral-hormonal channel.

On the day of the exam, a rhythmocardiographic examination was performed once again. The statistical analysis of HRV under conditions of emotional stress in students with vago- and normotonia revealed a significant decrease in SDNN ( $\mathrm{p}<0.05)$. The obtained values were characterized as a decrease in vagotonus activity in the groups.

Changes were also observed in pNN50 values. This indicator in all the groups significantly decreased $(p<0.05)$. It indicated a decrease in the parasympathetic effect on myocardial function.

Significant changes in the studied parameters of the heart also occurred under conditions of emotional stress.

A significant decrease $(\mathrm{p}<0.05)$ of the variational range values in students with vago- and normotonia was stated. In students with sympathotonics only a trend to a decrease was noted.

Characterizing the activity of parasympathetic tonicity markers, it is noted that pNN50 is more sensitive in the conditions of the examination session.

Under conditions of emotional stress, the analysis of the sympathetic nervous system state was carried out on the basis of the values of AMo and IN.

As it is known, the stabilizing effect of the heart rhythm control centralization is determined by sympathetic effects. This mechanism is reflected in the AMo indicator. The study established that under the influence of the stress factor (in this case, taking the exam), the AMo indicator significantly increased ( $\mathrm{p}<0.05)$ only in students with normotonia. The strain index, as a criterion for the degree of the functional reserves mobilization under the influence of disturbing factors, is associated primarily with an increase in the activity of the sympathetic department of the ANS. Under conditions of emotional stress in students with vago- and normotonia, the strain index increased significantly, while for the examined sympathotonics, no such changes were found. The increase in IN was different among the students with vago-, normo-, and sympathotonia. This indicator increased in the studied groups by $3.23,1.91$ and 1.08 times respectively. Thus, under the conditions of emotional stress, the equalization of IN value between the examined groups was noted.

A characteristic feature of the heart work under stressful conditions is the maintenance of its productivity (up to maximum values), adequate to the degree of impact. The activation of the ANS sympathetic department leads to a smoothing of the heart rhythm. It is accompanied by an increase in indicators such as AMo and IN [2,15].

\section{Conclusions}

Based on our data and the above literature review, it can concluded that the following factors were significantly affected by the stress factor: strain index and the share of neighboring RR-intervals, which differ by more than $50 \mathrm{~ms}$. If IN significantly increased in students with vago- and normotonia, pNN50 significantly decreased in all the examined groups. A similar factual material was obtained by a number of authors who studied heart rate variability in people under examination stress [1,6,8,11,17,19,20,21,22,23]. 


\section{References}

1. L.K. Budukool, A.M. Khovalyg, A.F. Kharrasov, The Bulletin Natural and agricultural sciences, 2, 18-26 (2017)

2. R.M. Baevskiy, Yu.N. Semenov, A.G. Chernikova, The analysis of heart rate variability with the help of the complex "Varicard" and the problem of defining functional states (Science, M., 167-178, 2000)

3. N.P. Devaev, Physiology. The bulletin of the Nizhny Novgorod University named after N.I. Lobachevskiy. 2(2), 622-626 (2010)

4. D.A. Dimitriev, E.V. Saperova, The main patterns of the formation of exam stress in students (Chuvash State Pedagogical University, Cheboksary, 2009)

5. O.A. Zhilina, A.V. Gryaznykh, New researches, 1-2(6), 165-166 (2004)

6. Yu.V. Kashina, Fundamental researches, 10-3, 514-517 (2014)

7. S.A. Kotelnikov, Human physiology, 28(1), 130-143 (2002)

8. A.N. Guerasevich, L.A. Shitov, E.G. Parkhots, Heart rhythm and type of autonomic regulation in assessing the level of public health and functional fitness of athletes: the materials of VI All-Russian symposium (Publishing center "Udmurt University", Izhevsk, 103-107, 2016)

9. E.A. Yumatov, O.S. Glazachev, E.V. Bykova, Psychophysiology of emotions and emotional strain of students (ITRK, Moscow, 2017)

10. R.A. Ginullin, A.P. Isaev, V.V. Erlikh, Yu.V. Korableva, Theory and practice of physical education, 3, 17-19 (2016)

11. V.R. Safonova, E.Yu. Shalamova, Human ecology, 8, 11-16 (2013)

12. L.N. Smelysheva, Collection of scientific works of scientists of the Ural Federal District (VISLA, M., II, 36-40, 2005)

13. E.A. Umryukhin, T.D. Dzhebrailova, I.I. Korobeynikova, Psychological journal, 26(4), 57-65 (2005)

14. N.V. Fomyugina, The successes of modern natural science, 4, 75-76 (2005)

15. L.D. Tsaturyan, Heart rate variability: Theoretical aspects and practical applications: the materials of IV AllRussian symposium (UdSU, Izhevsk, 324-327, 2008)

16. Yu.V. Scherbatykh, Higher education in Russia, 3, 53-56 (2000)

17. O.V. Yukovenko, Heart rhythm and type of autonomic regulation in assessing the level of public health and functional fitness of athletes: Materials of VI All-Russian symposium (Publishing center "Udmurt University", Izhevsk, 297-300, 2016)

18. Heart rate variability: Standards of Measurement, Physiological interpretation and clinical use, Circulation, 93, 1043-1065 (1996)

19. A.S. Ushakov, N.E. Kleshchenkova, A.V. Nenasheva, Theory and practice of physical education, 3, 20-22 (2016)

20. Y. Liu, Educational Psychology, 31(1), 27-35 (2011)

21. J. Taelman, S. Vandeput, A. Spaepen et al, 4th European Conference of the International Federation for Medical and Biological Engineering, 22, 1366-1369 (2009)

22. I. Tonhajzerova, Ceskoslov. Pediatr, 55(9), 562 - 567 (2000)

23. Aleksandr S. Kuznetsov, Zinaida M. Kuznetsova, Russian Journal of Physical Eduction and Sport, 14(4), 5-7 (2019) 